\title{
El ciclo de Guiron le Courtois. A propósito de la edición crítica dirigida por Lino Leonardi y Richard Trachsler ${ }^{1}$
}

\author{
Carlos Alvar \\ Universidad de Alcalá/IEMSO \\ carlos.alvar@uah.es
}

El 5 de febrero de 1240, una carta de la cancillería del emperador Federico II de Sicilia alude a «los LIIII cuadernos escritos del libro de Palamedes, que fueron del maestro Iohannes Romanzor», y de poco más tarde, antes de 1270, es el manuscrito más antiguo conservado de la Continuación de Guirón. Para entender estas primeras referencias conviene señalar que el denominado «Ciclo de Guiron le Courtois» está formado por tres textos principales: Roman de Meliadus, Roman de Guiron y Suite Guiron; son numerosas las ramificaciones, o «expansiones laterales», que surgen de esas tres historias. En ocasiones, la obra se denomina Palamedes, título que no responde a la realidad de su contenido: las tres partes o historias de que se compone el ciclo dan una idea bastante cercana, si no del contenido, sí del nombre del protagonista de cada una de las divisiones. Meliadús fue el padre de Tristán de Leonís, con lo que ya podemos sospechar que los hechos narrados comienzan en un período anterior a las hazañas de los caballeros de la Mesa Redonda. Por otra parte, es un personaje absolutamente desconocido en la tradición artúrica y solo lo encontramos en el ciclo de Guirón y en las versiones más tardías del Tristán en prosa y sus derivaciones, incluidas las obras italianas, debido al peso de la Compilation de Rustichello de Pisa. En cuanto a Guirón, en vano buscaríamos su nombre en los miles de páginas anteriores al ciclo que ahora nos interesa: así, el autor del texto ha tenido que inventarle una genealogía y buscar unas buenas razones que justificaran su ausencia del ámbito de los caballeros artúricos: ¿hay mejor recurso que contar de forma retrospectiva su larga prisión y su reciente libertad, que le ha permitido incorporarse a las aventuras de todos los demás?

${ }^{1}$ Il Ciclo di Guiron le Courtois. Romanzi in prosa del secolo XIII (2020). En contra de lo que anuncia el título y la publicidad de la editorial, la obra de Bubenicek (2015) no es una edición del texto que ahora nos ocupa, sino de una Suite marginal; cfr. al respecto Vox Romanica, 75 (2016), pp. 307-329. 
El influjo de la Vulgata artúrica y del Tristán en prosa (versión I) se dejan sentir en no pocas ocasiones, lo que permite situar la fecha de la primera redacción de Guirón el Cortés en torno a 1235 (Lathuillère 1966)2.

El anónimo autor, que se esconde bajo el pseudónimo de Hélie de Boron, igual que en el Tristan en prosa, lleva a cabo el relato de las aventuras de los caballeros de la generación anterior a los miembros de la corte artúrica o de la Mesa Redonda: los padres de todos ellos, incluido Uterpandragón, progenitor de Arturo, participan de los acontecimientos narrados. Así, no sorprende el éxito, pues el aplicado autor de Guiron le courtois aprovecha el entusiasmo suscitado por los grandes relatos en prosa y da vida a personajes conocidos por el público, gracias a las hazañas caballerescas y aventuras amorosas que ya habían realizado sus hijos y que eran bien sabidas por todos. Y, por si esto fuera poco, el autor ha hecho lo posible para convertir a su héroe en modelo profano de cortesía, en representante «de un ideal moral compuesto de lealtad, honor y generosidad» (Lathuillère 1966: 14), como vamos a ver a continuación.

Uno de los ejes de la narración se basa-como es normal-en las hazañas de los caballeros principales; el otro eje-también habitual- es el de las relaciones amorosas: la Dama de Malohaut, casada con su amigo Danaín, se enamora apasionadamente del protagonista, al que intenta seducir por todos los medios, sin éxito, gracias a que Guirón antepone la lealtad que debe al amigo frente a cualquier sentimiento movido por la belleza de la Dama; sin embargo, hay un momento de flaqueza y cuando está a punto de caer vencido por los encantos de la mujer y por el lugar, propicio al amor, desenvaina la espada que le dio Héctor el Bruno, en cuya hoja se podía leer: «Lealtad lo supera todo y Traición humilla a los hombres en los que se alberga». El contraste con la actitud de Danaín es muy significativo, ya que rapta a Bloie, amada de Guirón, en un momento en que éste no puede acudir a su lado... Entre las virtudes corteses de Guirón (amabilidad, trato agradable, facilidad de palabra, elegancia en el comportamiento, etc.) está también su habilidad musical, tanto con el arpa, como a la hora de componer lais, igual que Tristán de Leonís, al que se asemeja también en otros aspectos.

Así, pues, Guiron le Courtois es un digno representante de las tendencias de la narrativa francesa en prosa a mediados del siglo xIII, y forma parte del grupo de textos que se desarrollaron desde comienzos del siglo como enormes ciclos de aventuras de caballeros vinculados al Grial, o a la corte del rey Arturo: Lanzarote y los miembros de la Mesa Redonda; Tristán y los caballeros de Cornualles, que no tardan en unirse a los del reino de Logres en su búsqueda; Palamedes y Guirón, con sus compañeros llegan desde otros ámbitos: casi podríamos decir que salen de las brumas sin que nadie sepa quiénes son.

${ }^{2}$ Para Lagomarsini (2020: 3) -responsable del vol. IV de Il ciclo di Guiron le Courtois-, la gran compilación comenzó a partir de los años 1235-1240. 
Estos voluminosos textos han sido objeto, a lo largo del siglo xx, de ediciones fiables y estudios monográficos dedicados a cada una de las piezas del ciclo, en especial, en lo que se refiere a la Vulgata artúrica ${ }^{3}$. El Tristan en prose, de compleja tradición textual, tuvo que esperar algunas décadas a que se fijara una versión aceptable, dada la multiplicidad de testimonios, en los que se hizo imperativo poner orden; mientras tanto, los acercamientos al texto se basaron en los trabajos meticulosos de Eilert Löseth (1890) y de Cedrid Edward Pickford (1960), en los que quedó bien de manifiesto la relación entre el Tristán en prosa y el denominado Palamedes (es decir, el Guiron le Courtois); a pesar de todo, hubo que esperar a que la monografía de Emmanuèle Baumgartner (1975) estableciera las bases necesarias para la edición crítica del texto. Aun así, las diferencias entre unas ramas de la tradición textual y otras eran tan importantes, que los editores optaron por escoger como base el manuscrito más representativo, lo que no resolvía el problema, pero sí facilitaba el acceso a algunas versiones ${ }^{4}$.

En cuanto al Guiron le Courtois, su llegada a la edición crítica ha sido más tardía, aunque los especialistas han podido contar, para trabajar sobre la obra, con las referencias contenidas en los libros de Löseth y de Pickford, y, sobre todo, con el estudio y amplio análisis crítico - de más de 350 páginas- de Roger Lathuillère, realizado sobre el manuscrito 350 de la Bibliothèque nationale de France, aunque con el apoyo de otros testimonios para rellenar lagunas (Lathuillère 1966: 106 y 107-122). Sin embargo, la tarea no resulta tan fácil como aparenta, ya que se han conservado una treintena de manuscritos y solo el análisis minucioso de cada uno de ellos puede ayudar a establecer las varias familias textuales $\mathrm{y}$, en consecuencia, los testimonios válidos y los desechables por motivos diversos 5 .

En todo caso, Guiron le Courtois se sitúa en la senda que lleva desde el Tristán en prosa a la Compilación de Rustichello de Pisa (h. 1270), modelo de traducciones y reelaboraciones italianas, desde textos elevados como los de Boiardo y Ariosto, hasta los más populares, como los cantari, pasando por La Tavola Ritonda y, por los diferentes Tristanes (Riccardiano, Panciatichiano, etc.).

${ }^{3}$ La Queste del Saint Graal, ed. de Pauphilet (1923), aunque hay una edición más moderna de Bogdanow (2006); La Mort le Roi Artu, ed. de Frappier (1936), pero, también, ed. de Hult (2009); Lancelot, ed. de Micha (1978-1983), y Merlin, ed. del mismo Micha (1979); L'Estoire del saint Graal, ed. de Ponceau (1997). Para los estudios, citaré los más representativos: Pauphilet (1921), Lot (1948), Frappier (1972) y Micha (1980).

${ }^{4}$ Le Roman de Tristan en prose (basado en el ms. 404 de la Bibl. munic. de Carpentras), ed. de Curtis (1985); Le Roman de Tristan en prose (basado en el ms. 2542 de la Oesterreische Nationalbibliothek Wien), dir. de Ménard (1987-1997); y Le roman de Tristan en prose (basado en el BnF, ms. fr. 757), dir. de Ménard (1997-2007).

${ }^{5}$ Morato (2010), Lagomarsini (2018) y Leonardi/Morato (2018). 
La reciente publicación de la edición crítica del Roman de Guiron y de su Continuación, segunda y tercera partes del ciclo, viene a llenar un vacío inexplicable, por la importancia del texto en sí mismo y por la gran difusión que tuvo a finales de la Edad Media.

Esta edición destaca por ser propiamente una edición crítica, gracias al planteamiento ecdótico que han seguido los editores, y que dista mucho de los principios aplicados habitualmente en las colecciones al uso entre los medievalistas franceses, de tradición «bédieriana», proclives al establecimiento del manuscrito mejor $y$, en consecuencia, a su edición con el apoyo de algunos otros testimonios.

Los tres volúmenes que nos ocupan se abren con el mismo texto, justificativo de «l'edizione del Gruppo Guiron». Se trata de una breve presentación, de apenas ocho páginas, en las que los coordinadores, Lino Leonardi y Richard Trachsler, explican con claridad en qué consiste el ciclo de Guirón, el status quaestionis, los trabajos realizados por el equipo editor, con las conclusiones sobre la tradición textual y, finalmente, las características de la edición crítica que tenemos entre las manos. La claridad de los distintos aspectos -algunos de extrema complejidad- es un modelo de trabajo bien meditado, dirigido a buenos conocedores de la materia y a quienes no la conocen tan bien. No se trata de la aplicación más o menos mecánica de un método, sino de establecer el texto sin adoptar un manuscrito de base, pero siguiendo las indicaciones suministradas por el stemma, para eliminar del texto crítico las variantes sustanciales que se han introducido a lo largo de su transmisión. «Hemos respetado, pues, un procedimiento riguroso de selección de las variantes sustanciales adiáforas: han sido excluidas del texto crítico, porque se juzgaron innovadoras en el stemma, las variantes transmitidas por un solo manuscrito o por una sola subfamilia; en los casos de aposición entre una rama y otra del stemma, se ha seguido siempre la misma rama, la más conservadora» (p. XIV).

Para poder fijar las variantes formales con el mismo rigor, los editores han procedido a cruzar los criterios de sustancia textual / forma lingüística, con los conceptos de monogénesis / poligénesis lo que les ha permitido establecer una serie de criterios para aislar los fenómenos de variación propios de estructuras fundamentales codificadas $-\mathrm{y}$, por tanto habituales- en la lengua literaria de la prosa artúrica: copistas familiarizados con estos textos pueden dar lugar a los mismos resultados sin partir del mismo modelo. Ese tipo de variantes queda excluido, porque en sí mismo no aporta información pertinente: el aparato de variantes se basa, pues, en una selección consciente y coherente, que queda preestablecida con claridad, aligerando el esfuerzo que tendría que realizar el lector interesado.

Este planteamiento y la aplicación de los criterios de competencia y plausibilidad de unos manuscritos, con respecto a otros, dan como 
resultado la selección de un «manuscrito de superficie» o «superficial». Quizás lo más relevante -aunque previsible- en este sentido sea la importancia de las copias italianas, frente a la elección de Lathuillère, que prefirió el ms. fr. 350 por ser el más completo, y que ahora queda relegado por su manifiesta hibridación o contaminación ${ }^{6}$.

Cada uno de los volúmenes se diferencia a partir de esta breve introducción, aunque los dos volúmenes del Roman de Guiron y el volumen de la Continuación mantienen una estructura similar, ya que se trata de la edición de testimonios, manuscritos diferentes con características de transmisión y lengua, también dispares: siguiendo un planteamiento inobjetable, aunque extraño, cada volumen tiene su propio glosario, su propia bibliografía y su propio índice de nombres de personajes, lugares e instituciones mencionados en el texto. Los editores han mantenido la individualidad de cada códice «de superficie», aun tratándose de una sola obra literaria (o dos, si se considera la Continuación como independiente del Roman de Guiron).

El resultado de muchos años de trabajo, casi dos décadas, ha permitido a los editores establecer la existencia de una «genealogía general de la tradición» textual: tres núcleos iniciales que dieron lugar a un ciclo; el primero de ellos tuvo como protagonista a Meliadús, el padre de Tristán: la rama más antigua surgió de forma independiente de los otros textos y representa un estado «pre-cíclico»; se trata de manuscritos de origen italiano, copiados a partir de los últimos años del siglo xIII y a lo largo del siglo XIV. Luego, otra rama, ya de carácter cíclico, con manuscritos de origen francés y flamenco, copiados desde mediados del siglo XIV hasta finales del siglo xv; de este grupo derivan los manuscritos parisinos $\mathrm{y}$, por otra parte, los del nordeste francés... El manuscrito 350, utilizado por R. Lathuillère como base de su minucioso trabajo pertenece al subgrupo parisino (copiado en Arras) y no siempre resulta fácil de establecer su itinerario textual debido a los cruces, por lo que para los editores resulta de menor autoridad que las copias italianas.

El panorama que se deduce de estas conclusiones es rico y del mayor interés: en primer lugar, el método neolachmanniano aplicado con rigor y espíritu crítico ha permitido establecer que, en el caso de Guiron le Courtois al menos, no existe un único lugar de creación de los componentes del ciclo y de difusión de la obra. No hay, pues, un texto de base copiado y recopiado, con errores y lagunas, sino textos independientes que se unen en un momento concreto.

En segundo lugar, se plantea una cuestión fundamental para las novelas en prosa de inspiración artúrica: si no se edita el manuscrito más completo o más extenso, ¿qué texto se debe publicar? La respuesta es clara, aunque exige esfuerzos, tiempo y conocimientos, además de un

\footnotetext{
${ }^{6}$ Véase al respecto Stefanelli (2018).
} 
equipo de trabajo de excelente preparación, como es el que constituye el «Gruppo Guiron»: el más cercano a la versión primera; es obvio que este proceder obliga a prescindir de adherencias, añadidos y alteraciones que no formen parte del arquetipo. Es natural que esta decisión, por más meditada y justificada que esté, puede sorprender, pero hay que considerar más el provecho que aporta, que el perjuicio que podría producir: la discusión ya se encuentra desde los orígenes de la ecdótica como ciencia, pero es obvio que solo así, podremos estar seguros de que, al menos, lo que leemos, por incompleto o imperfecto que sea, pertenece a un momento histórico, cultural o ideológico bien concreto. En el caso contrario, son tantas las dudas, que pueden llegar a convertir una edición en inservible, ya sea por las modernizaciones lingüísticas o por la superposición de elementos que pueden resultar anacrónicos: es cierto que los bedieristas tienen razón al argumentar que, al menos, se lee un texto que realmente existe y no un «constructo» del estudioso; no obstante, sí que es conveniente marcar los límites cronológicos, la estratigrafía textual. No se debe olvidar que los textos en prosa tuvieron una vida muy larga, una difusión muy amplia y que fueron traducidos a varias lenguas: la desaparición de manuscritos no facilita el trabajo del editor crítico y, a veces, hay que suponer la existencia de textos que se han perdido en el transcurso del tiempo; pero en otras ocasiones, se hace imprescindible una disección pormenorizada, que facilite la interpretación de los materiales que han sobrevivido. Así, por ejemplo, solo a partir del minucioso trabajo de Emmanuèle Baumgartner se pudo entender la tradición del Tristan en prose.

Entre las supresiones que ha sufrido el análisis de Lathuillère es significativa la que afecta a un breve episodio protagonizado por Palamedes: a partir del $\S 262$, el autor cuenta que el caballero, después de dejar al rey Arturo, cabalgó hasta llegar a un bosque en el que oyó a lo lejos un gran ladrido, como de treinta perros o más. Al acercarse ve

Une moult estrange beste, grande de corps, assez plaisante a regarder et de poil et de façon, laquelle façon est devisee en aulcunes histoires ou des vaillances de Palamedes fait mention plus au long qu'il n'en est parlé en ce conte. (Lathuillère 1966: 492-494) ${ }^{7}$.

Palamedes inicia su persecución del animal, lo que le valdrá el apelativo de Caballero de la «Beste glatissant» (Bestia Ladradora), pero -señala el autor de la obra- «no he visto cuento, o historia, en que se contenga

${ }^{7}$ El epíteto de Palamedes es utilizado en otras ocasiones, sin más explicación que la de haber perseguido al extraño animal en vano, como ocurre en $\$ 282$, p. 517; sin embargo, la persecución no constituye un eje del relato, paralelo a la búsqueda del Grial, pero de signo pagano, como en textos posteriores. 
que dio fin a su persecución». Tras el primer fracaso en la caza del animal, Palamedes reemprende su camino. Tras varias aventuras, el caballero oye de nuevo el ladrido y sale en busca de su origen, pero de nuevo fracasa. Ahora se dirige a la corte del rey Arturo, acompañado por una doncella que comprende que se trata de Palamedes, al que iba buscando para que defienda su causa frente a Gohors, que le ha robado sus posesiones. Vence al usurpador y le corta la cabeza; la doncella se habría casado con él, si no fuera pagano. Juntos van a un torneo en el que Palamedes participa con la figura de la «beste glatissant» pintada en su escudo y, con la ayuda de su hermano Saphar, vencen el torneo y, luego, acompañan a la doncella a sus tierras donde permanecen hasta después de las bodas de la joven con un noble del lugar. Los dos hermanos se dirigen a la Torre Dolorosa, combaten contra Caradoc en varios encuentros y lo derrotan. Aquí deja el cuento de hablar de esta guerra y vuelve a hablar del rey Marc de Cornualles y de Alejandro el Huérfano, su sobrino.

El episodio citado se encuentra en el ms. fr. 362 de la BnF, que forma parte de un extenso conjunto de seis volúmenes (fr. 358-363) realizado en Flandes para Lodevijk van Gruuthuse, señor de Brujas, en el último cuarto del siglo Xv (ed., IV, pp. 31-32) y las razones de su exclusión, con la desaparición o, mejor, «no aparición» de Palamedes fueron ya motivo de análisis por parte de Claudio Lagomarsini y quedan recogidas por Elena Stefanelli en el vol. V de la ed., p. 870, n. 1401.4. En todo caso, es evidente que un manuscrito tan tardío como éste, testimonio único de la presencia de la «Beste glatissant» en el ciclo de Guirón, hace sospechar de la fiabilidad de la referencia y más, cuando resultan evidentes las manipulaciones y alguna rayadura del texto. Así, al trazar la historia del esquivo animal habrá que pensar que su presencia en algunos textos se debe a aportaciones individuales, que nada tienen que ver con la tradición: en definitiva, que se trata de contaminaciones o, si preferimos, de ramas nuevas del tronco original; no desechables, pues sirven para construir una posible lectura de las obras.

El volumen VI de esta edición corre a cargo de Marco Veneziale y en él se publica una Continuación del ciclo casi desconocida, correspondiente a los $\S \S 133-150$ de Lathuillère. El título (Continuación) es meramente utilitario, ya que no pertenece a la tradición, pero que sirve para definir el tipo de texto de que se trata. En efecto, este volumen VI es un texto que continúa el Roman de Guiron, que había quedado inacabado; así pues, sigue formando parte de la segunda rama, de la que sería una especie de apéndice, presente solo en dos de los manuscritos, con un único testimonio completo.

Falta aún por publicar (será el vol. VII) la Suite Guiron, texto que muy posiblemente sirve de enlace entre el Meliadus y el Guiron y que es la tercera rama del ciclo. 
Ya Richard Trachsler había señalado cómo una gran parte de los textos artúricos terminan en el mismo lugar en el que se detienen las ediciones modernas, lo que no hace necesario plantearse la cuestión de continuaciones o suites. No se trata de una cuestión terminológica o un dilema retórico, sino de un problema de fondo, ya que afecta a la finalización de la obra: si carecemos de un final avalado por la tradición textual, será imposible decidir cuándo un fragmento de texto pertenece a una continuación o a una suite (Trachsler 1996: 195-196). Nicola Morato (2010) había considerado que el «momento conclusivo» no remontaría al arquetipo original del Roman de Guiron, sino que formaría parte del marco del ciclo, mientras que según Veneziale, el hecho de que el episodio sea transmitido de forma unánime por dos manuscritos da la certeza de que ya se encontraba en el original. Así, habría que aceptar que se trata de una continuación más que de una suite (ed., pp. 5-9).

En una nota de este tipo no se pueden señalar todos los aspectos positivos de una edición crítica como la dirigida por Leonardi y Trachsler. Ya la publicación de los volúmenes que han visto la luz es suficiente motivo para reconocer el esfuerzo filológico, el ejercicio ecdótico y los grandes logros alcanzados. Estoy seguro de que durante mucho tiempo seguiremos hablando de estos volúmenes y de la profunda sabiduría del «Gruppo Guiron», porque marcan una nueva forma de analizar las extensas narraciones artúricas medievales.

La pluralidad de centros de producción, el desarrollo geográfico y cronológico de los textos, y el trabajo ecdótico llevado a cabo han dado un impulso nuevo a una obra de primera magnitud, de la que apenas se ocupaba la crítica. No hay duda de la importancia de esta edición, por su calidad y porque abre nuevas vías al conocimiento.

\section{REFERENCIAS BIBLIOGRÁFICAS}

Il Ciclo di Guiron le Courtois. Romanzi in prosa del secolo XIII (2020). Ed. crítica. Lino Leonardi y Richard Trachsler (dirs.). Firenze: Edizioni del Galluzzo per la Fondazione Ezio Franceschini:

- Vol. IV. Roman de Guiron. Parte prima. Claudio Lagomarsini (ed. y coord.). $897 \mathrm{pp}$.

- Vol. V. Roman de Guiron. Parte seconda. Elena Stefanelli (ed. y coord.). $920 \mathrm{pp}$.

- Vol. VI. Continuazione del Roman de Guiron. Marco Veneziale (ed. y coord.). $530 \mathrm{pp}$.

BAUMgartner, Emmanuèle (1975), Le "Tristan en prose». Essai d'interprétation d'un roman médiéval. Genève: Droz.

BUBENICEK, Venceslas (2015), «Guiron le Courtois». Roman arthurien en prose du XIII siècle. 2 vols. Berlin/Boston: De Gruyter.

FrapPIER, Jean (1972), Étude sur «La Mort le Roi Artu». Paris: Champion. 
L'Estoire del saint Graal (1997), Jean-Paul Ponceau (ed.). 2 vols. Paris: Champion.

La Mort le Roi Artu (1936), Frappier, Jean (ed.). Genève: Droz.

La Mort le Roi Artu (2009), Hult, David F. (ed.). Paris: Librairie générale française.

Lagomarsini, Claudio (2018), «Pour l'édition du Roman de Guiron. Classement des manuscrits», en Lino Leonardi y Richard Trachsler (dirs.), Le cycle de «Guiron le Courtois». Prolégomènes à l'édition intégrale du corpus. Estudios recopilados por L. Cadioli y S. Lecomte. Paris: Classiques Garnier, pp. 249-430

Lancelot (1978-1983), Alexandre Micha (ed.). 9 vols. Genève: Droz.

LATHUILLÈRE, Roger (1966), «Guiron le courtois». Étude de la tradition manuscrite et analyse critique. Genève: Droz, pp. 31-34.

Le Roman de Tristan en prose (1985), Renée L. Curtis (ed.). 3 vols. München/Cambridge: Hueber-Brewer.

Le Roman de Tristan en prose (1987-1997), Philippe Ménard (dir.). 9 vols. Genève: Droz.

Le Roman de Tristan en prose (1997-2007), Philippe Ménard (dir.). 5 vols. Paris: Champion.

LEONARDI, Lino y Nicola Morato (2018), «L'édition du cycle de Guiron le Courtois: établissement du texte et surface linguistique», en Lino Leonardi y Richard Trachsler (dirs.), Le cycle de "Guiron le Courtois». Prolégomènes à l'édition intégrale du corpus. Estudios recopilados por L. Cadioli y S. Lecomte. Paris: Classiques Garnier, pp. 453-510.

LöSETH, Eilert (1890), Le roman en prose de Tristan. Le roman de Palamède et la compilation de Rusticien de Pise. (Analyse critique d'après les manuscrits de Paris). Paris: Champion [Genève: Slatkine, 1974].

Lot, Ferdinand (1948), Étude sur le «Lancelot en prose». Paris: Champion. Micha, Alexandre (1980), Étude sur le «Merlin», de Robert de Boron. Genève: Droz.

Morato, Nicola (2010), Il ciclo di «Guiron le Courtois». Strutture e testi nella tradizione manoscritta. Firenze: Edizioni del Galluzzo per la Fondazione Ezio Franceschini.

Pauphilet, Albert (1921), Études sur la «Queste del Saint Graal». Paris: Champion.

PiCKFORD, Cedric Edward (1960), L'évolution du roman arthurien en prose vers la fin du Moyen Âge (d'après le manuscrit 112 du fonds français de la Bibliothèque nationale). Paris: Nizet.

Robert de Boron (1979), Merlin. Alexandre Micha (ed.). Genève: Droz. Queste del Saint Graal (1923), Albert Pauphilet (ed.). Paris: Champion, Queste del Saint Graal (2006), Fanni Bogdanow (ed.). Paris: Librairie générale française.

Stefanelli, Elena (2018), «L'édition du Roman de Guiron. Choix des manuscrits de surface», en Lino Leonardi y Richard Trachsler (dirs.), 
Le cycle de "Guiron le Courtois». Prolégomènes à l'édition intégrale $d u$ corpus. Estudios recopilados por L. Cadioli y S. Lecomte. Paris: Classiques Garnier, pp. 541-563.

Trachsler, Richard (1996), Clôtures du cycle arthurien. Genève: Droz, pp. 195-196.

Recibido: $1 / 10 / 2021$

Aceptado: 14/10/2021

$\cos$

\section{El CiClo de GUiRon le CoURtois. \\ A PROPÓSITO DE LA EDICIÓN CRÍTICA DIRIGIDA POR \\ LINO LEONARDI Y RICHARD TRACHSLER}

Resumen: En esta larga nota se sitúa el ciclo de Guiron de Courtois en su contexto de la literatura francesa del siglo XIII dedicada a la materia de Bretaña. El interés de este extensísimo ciclo va más allá, pues es el eslabón necesario con la rica tradición italiana iniciada por Rustichello de Pisa. De forma inexplicable, el Ciclo había quedado inédito aunque era conocido por los estudiosos. El análisis de esta edición crítica revela la utilidad de la aplicación del método «neolachmanniano» y la riqueza que conlleva, al establecer el «manuscrito de superficie» que permite un acercamiento riguroso a los posibles orígenes de cada una de las partes que constituyen la narración.

Palabras-Clave: Guiron le Courtois. Método «neolachmanniano». Materia de Bretaña. Ciclos caballerescos. Novela en prosa medieval. Rustichello de Pisa.

THE GUIRon le COURTOIS CYCLE.

ABOUT THE CRITICAL EDITION DIRECTED BY LINO LEONARDI AND RichARD TRACHSLER

AbSTRACT: In this long note, we place the Guiron le Courtois cycle in its context of 13th century French literature on the matter of Britain. The interest of this very extensive cycle goes further, because it is the necessary link with the rich Italian tradition initiated by Rustichello da Pisa. Inexplicably, the Cycle had remained unpublished although it was known to scholars. The analysis of this critical edition reveals the usefulness of the application of the Neolachmannian method and the richness that it entails, by establishing the «surface manuscript» that allows a rigorous approach to the possible origins of each of the parts that comprise the narration.

Keywords: Guiron le Courtois. Neolachmannian method. Matter of Britain. Chivalric romance. Medieval prose novel. Rustichello da Pisa. 